\title{
Knowledge and practices regarding biomedical waste management among healthcare professionals in tertiary care hospitals of Mangalore, India
}

\author{
Ramesh Holla ${ }^{1}$, Bhagawan B. Darshan ${ }^{1}$, Nidhika Sorake ${ }^{2}$, Bhaskaran Unnikrishnan ${ }^{1}$, \\ Rekha Thapar ${ }^{1}$, Prasanna Mithra ${ }^{1}$, Nithin Kumar ${ }^{1}$, Vaman Kulkarni ${ }^{1}$, Avinash Kumar ${ }^{1}$
}

\footnotetext{
${ }^{1}$ Department of Community Medicine, Kasturba Medical College (Manipal University), Mangalore, Karnataka, India

${ }^{2}$ Undergraduate Medical Student, Kasturba Medical College (Manipal University), Mangalore, Karnataka, India
}

Received: 25 September 2015

Accepted: 10 October 2015

\section{*Correspondence:}

Dr. Ramesh Holla,

E-mail: 13rameshholla@gmail.com

Copyright: (C) the author(s), publisher and licensee Medip Academy. This is an open-access article distributed under the terms of the Creative Commons Attribution Non-Commercial License, which permits unrestricted non-commercial use, distribution, and reproduction in any medium, provided the original work is properly cited.

\section{ABSTRACT}

Background: Infections occurring from waste produced in health care establishments are more when compared to any other type of waste. There is inadequate and inappropriate knowledge of biomedical waste management among health care personnel which might have serious health consequences and pose a threat to the environment. This study was conducted to determine the knowledge of health care professionals about the proper disposal of biomedical waste and practice in following preventive measures while handling bio medical waste.

Methods: This cross sectional study was conducted at three tertiary care teaching hospitals attached to Kasturba Medical College (KMC), Mangalore. Health care professionals comprising of doctors, nurses, lab technicians and class IV employees were enrolled in the study based on convenient sampling technique after obtaining their informed written consent. The data was collected using a pre tested, semi structured questionnaire. SPSS Version 16.0 was used for entering the data and analysis.

Results: It was found that doctors had better knowledge compared to other health care professionals about the correct disposal of needles $(n=56,84.8 \%)$ and disposal of discarded medicines $(n=45,68.2 \%)$. Knowledge about the correct disposal of tubes and catheters were almost equal among doctors $(\mathrm{n}=47,71.2 \%)$ and nurses $(\mathrm{n}=47,73.4 \%)$. Only $44.5 \%(n=97)$ of health care professionals were utilizing all the personal protective equipments while handling bio medical waste.

Conclusions: It can be concluded that the awareness regarding proper disposal of biomedical waste was better among doctors, staff nurses and lab technicians when compared to class IV employees.

Keywords: Knowledge, Bio medical waste, Health care professionals

\section{INTRODUCTION}

Biomedical waste has been defined as the "waste generated in the diagnosis, treatment or immunization of human beings or animals in research or in the production of testing of biological products including all categories of infected and toxic waste that is potential threat to human being and environment (Government of India
1998). ${ }^{1}$ Only $10-25 \%$ of the waste produced at health care establishments are hazardous; whereas $75-90 \%$ of wastes are non-hazardous to health and the environment. ${ }^{1}$ Around 0.33 million tonnes of hospital waste is generated in India; which accounts to approximately 0.5 to $2 \mathrm{~kg}$ per bed per day per patient. $^{2}$ 
Infections occurring from waste produced in health care establishments are more when compared to any other type of waste. There is inadequate and inappropriate knowledge of biomedical waste management among health care personnel which might have serious health consequences and pose a threat to the environment. There have been a number of legislatures implemented to ensure proper disposal of biomedical waste in India which includes the following (Biomedical waste management and handling) Rules 1998 and Solid waste (Management and Handling) Rules 2000, Hazardous waste (Management and Handling) Rules 1989. ${ }^{3-5}$ These rules are applicable to every hospital and nursing home which generates biomedical waste. Adequate knowledge about the health hazards of hospital waste, proper preventive measures for handling waste can lead to safe disposal of hazardous waste and protect from the disease transmitted by them and also its adverse effects in such a way that it is safe for environment as well as community. Therefore proper management of biomedical waste is not only a legal necessity but also a social responsibility. ${ }^{6}$

Although there is an increase in global awareness among health care professionals about hazardous waste and appropriate management techniques but the level of awareness in India is found to be unsatisfactory. ${ }^{7-9}$ In this background, the present study was conducted to study the knowledge of the health care professionals about the proper disposal of biomedical waste in the hospital and also about the diseases transmitted by the biomedical waste. The study also aimed at assessing the practice of health care professionals in following preventive measures while handling bio medical waste.

\section{METHODS}

This cross sectional study was conducted at three tertiary care teaching hospitals attached to Kasturba Medical College (KMC), Mangalore. The Institutional ethics committee of the college had given approval for this study. Around 218 Health care professionals were individually approached during the study period and were explained about the objectives of the study. A written informed consent was taken from those who were willing to participate in the study. Health care professionals comprising of doctors, nurses, lab technicians and class IV employees were thus, enrolled in the study based on convenient sampling technique. The data was collected using a pre tested, semi structured questionnaire. The questionnaire consisted of information related to the knowledge and practices of healthcare professionals about biomedical waste and its management and also about the diseases transmitted by them. It also had information regarding practice of the health care professionals in following preventive measures on bio medical waste management. Questionnaire filled by the study participants were checked for its completeness and only the completed ones were considered for data analysis. SPSS (Statistical Package for Social Sciences) Version 16.0 was used for entering the data and analysis.

\section{RESULTS}

Table 1 shows the correct knowledge of healthcare professionals about the use of bin for disposal of biomedical waste. In this study, it was found that doctors had better knowledge compared to other health care professionals about the correct disposal of needles $(n=56$, $84.8 \%)$ and disposal of discarded medicines $(n=45$, $68.2 \%$ ). Knowledge about the correct disposal of tubes and catheters were almost equal among doctors $(n=47$, $71.2 \%)$ and nurses $(n=47,73.4 \%)$. Awareness about the proper disposal of anatomical waste was found to be better among the nurses $(n=56,87.5 \%)$ when compared to other health care professionals. The knowledge of lab technicians regarding proper disposal of body fluids $(n=29,67.4 \%)$ and cotton disposal $(n=38,88.0 \%)$ was found to be better than other health care professionals in the present study. It is evident from the study that class IV employees had lower knowledge towards proper disposal of biomedical waste when compared to other health care professionals.

Table 1: Correct knowledge of health care professionals about the bins to be used for disposal of bio medical waste $(n=218)$.

\begin{tabular}{|lllll|}
\hline Type of bio medical waste & $\begin{array}{l}\text { Doctors } \\
\mathbf{n}(\%)\end{array}$ & $\begin{array}{l}\text { Nurses } \\
\mathbf{n}(\%)\end{array}$ & $\begin{array}{l}\text { Lab technicians } \\
\text { n(\%) }\end{array}$ & $\begin{array}{l}\text { Class IV employees } \\
\text { n(\%) }\end{array}$ \\
\hline Disposal of needles & $56(84.8)$ & $54(84.4)$ & $32(74.4)$ & $30(66.7)$ \\
\hline Disposal of body fluids & $39(59.1)$ & $41(64.1)$ & $29(67.4)$ & $27(60.0)$ \\
\hline Disposal of cotton & $53(80.3)$ & $48(75.0)$ & $38(88.0)$ & $32(71.1)$ \\
\hline Disposal of tubes and catheters & $47(71.2)$ & $47(73.4)$ & $31(72.1)$ & $23(51.1)$ \\
\hline Disposal of anatomical wastes & $55(83.3)$ & $56(87.5)$ & $35(81.4)$ & $36(80.0)$ \\
\hline Disposal of discarded medicines & $45(68.2)$ & $39(60.9)$ & $27(60.5)$ & $20(44.4)$ \\
\hline
\end{tabular}

It was evident from the above table that majority of the health care professionals were aware of the fact that hepatitis $\mathrm{B}$ can be transmitted by the bio medical waste $(\mathrm{n}=137,62.8 \%)$. The knowledge regarding hepatitis $\mathrm{C}$ 
and HIV/AIDS being transmitted through biomedical waste was found to be minimal i.e. $04.1 \%(\mathrm{n}=9)$ and $26.1 \%$ (57) respectively. Details were shown in Table 2.

Table 2: Knowledge of health care professionals about the disease transmitted by the bio medical waste $(\mathbf{n}=\mathbf{2 1 8})$.

\begin{tabular}{|ll|}
\hline $\begin{array}{l}\text { Disease transmitted by bio } \\
\text { medical waste }\end{array}$ & \begin{tabular}{l} 
Number (\%) \\
\hline Hepatitis B
\end{tabular} \\
\hline Hepatitis C & $137(62.8)$ \\
\hline HIV/AIDS & $009(04.1)$ \\
\hline
\end{tabular}

Prevention measures taken by healthcare professionals while handling biomedical waste is shown in Table 3. It was observed that glove usage while handling bio medical waste was practiced only by one fourth of the health care professionals $(n=60,27.5 \%)$. Usage of goggles $(n=7,3.2 \%)$, masks $(n=3,1.4 \%)$, boots $(n=3$, $1.4 \%)$ and gowns $(\mathrm{n}=48,22.0 \%)$ were less commonly practiced among health care professionals. Only $44.5 \%$ $(n=97)$ of health care professionals were utilizing all the personal protective equipments while handling bio medical waste.

Table 3: Preventive measures taken by the health care professionals while handling bio medical waste $(n=218)$.

\begin{tabular}{|ll|}
\hline $\begin{array}{l}\text { Preventive measures } \\
\text { adopted }\end{array}$ & Number (\%) \\
\hline Gloves & $60(27.5)$ \\
\hline Goggles & $07(3.2)$ \\
\hline Masks & $03(1.4)$ \\
\hline Boots & $03(1.4)$ \\
\hline Gowns & $48(22.0)$ \\
\hline All of the above & $97(44.5)$ \\
\hline
\end{tabular}

\section{DISCUSSION}

The present cross-sectional study was carried out to assess the knowledge and practices of healthcare professionals about biomedical waste management in tertiary care hospitals of Mangalore. This study showed that out of 218 health care professionals doctors $(84 \%)$ had better knowledge compared to other health care professionals regarding disposal of biomedical waste, this finding was corroborated by the study done at Dhaka, Bangladesh; ${ }^{10}$ where doctors $(37 \%)$ had more knowledge than other cleaning staffs. Our study also showed that the knowledge about disposal of anatomical waste was higher among the nurses $(87 \%)$ which are distinct to study done in Dhaka, ${ }^{10}$ where doctors were more wellversed with proper disposal of anatomical waste.

A study done in Nursing homes of Delhi, India, ${ }^{11}$ where they compared the results of private nursing homes of South zone and East zone, they found that knowledge about disposal of bio medical waste in bins was good which was $75 \%$ in south zone and $85 \%$ in east zone. Only $13 \%$ in south zone and $9 \%$ in east zone were unaware of it. This is almost similar to our study which showed good knowledge among health care professionals regarding proper disposal of waste into the bins. A Saudi Arabian study in King Fahad Hospital University ${ }^{12}$ depicted that doctors, nurses and lab technicians had better knowledge than sanitary staff which is in line with our study findings.

If health care professionals are not sensitised about the disease transmission by biomedical waste they will put themselves and the community at the risk of various hazards. Diseases mainly transmitted by biomedical waste are Hepatitis B, Hepatitis C and HIV. In our study the knowledge among healthcare professionals about Hepatitis B transmission through improper disposal of biomedical waste was found to be better than other disease transmission. But a similar study done in Delhi, India $^{11}$ showed that knowledge of health care professionals about the spread of disease in South zone was $98 \%$ and in East zone was $98.2 \%$. A study done in tertiary care hospital of Bijapur, North Karnataka, India ${ }^{12}$ had coequal results with our study done in South Karnataka.

Adhering to the principles of standard precautions, various safety measures are taken by healthcare professionals during biomedical waste management. Majority of the participants adopted preventive measures like usage of goggles, gloves, mask, gowns and boots in our study. A study done in North India ${ }^{11}$ revealed that usage of gloves among healthcare professionals in hospitals of south zone was found to be $96 \%$ and east zone was $98 \%$. In a tertiary care setup of Bijapur ${ }^{13}$ it was found that majority of the hospital staffs were conscious of measures taken for safe collection and final disposal of biomedical waste which is almost similar to our study.

\section{CONCLUSION}

It can be concluded that the awareness regarding proper disposal of biomedical waste was better among doctors, staff nurses and lab technicians when compared to class IV employees. Despite having fairly good knowledge about the transmission of Hepatitis B through inappropriate disposal of biomedical waste, the lower usage of personal protective measures in day today handling of biomedical waste among the healthcare professionals is a matter of concern. Every effort should be made at the healthcare facility to ensure that all the health care professionals will be following the correct guidelines for the disposal of biomedical waste and adhering to the principles of standard precautions in order to prevent infection for themselves and the community. 


\section{ACKNOWLEDGEMENTS}

The authors wish to acknowledge the support provided by the Department of Community Medicine, Kasturba Medical college, Mangalore and Manipal University for conducting this research and also grateful to the study participants who took part in this study voluntarily.

Funding: No funding sources

Conflict of interest: None declared

Ethical approval: The study was approved by the institutional ethics committee

\section{REFERENCES}

1. Park K. Biomedical waste. In: Park K, eds. Park's Textbook of Preventive and Social Medicine. 23rd ed. Jabalpur: Banarsidas Bhanot; 2015: 788-789.

2. Patil AD, Shekdar AV. Health-care waste management in India. $\mathrm{J}$ Environ Manage. 2001;63(2):211-20.

3. The Gazette of India. Biomedical waste (Management \& handling) rules, 1998. Extraordinary, Part II, Section 3, Subsection (ii), India: The Gazette of India, No. 460; 27 July 1998.

4. Govt. of India. Hazardous wastes (Management and handling) rules. Ministry of Environment \& Forests. New Delhi: Govt. of India; 1989. Available at: http://envfor.nic.in/legis/hsm/hsm1.html. Accessed 12 July 2015.

5. Govt. of India. Municipal solid wastes (management and handling) rules. Ministry of Environment and Forests. New Delhi: Govt. of India; 2000. Available at: http://www.moef.nic.in/legis/hsm/mswmhr.html. Accessed June 2014.

6. Mathur V, Dwivedi S, Hassan M, Misra R. Knowledge, attitude, and practices about biomedical waste management among healthcare personnel: a cross- sectional study. Indian J Community Med. 2011;36(2):143-5.
7. Pandit NB, Mehta HK, Kartha GP, Choudhary SK. Management of biomedical waste: awareness and practices in a district of Gujarat. Indian J Public Health. 2005;49(4):245-7.

8. Rao PH. Report: hospital waste management awareness and practices: a study of three states in India. Waste Manage Res. 2008;26(3):297-303.

9. Kishore J, Goel P, Sagar B, Joshi TK. Awareness about biomedical waste management and infection co troll among dentists of a teaching hospital in New Delhi, India. Indian J Dent Res. 2000;11(4):157-61.

10. Sarkar MA, Harun-Or-Rashid M, Abdul Hai MS, Siddique MR, Sakamoto J, Hamajima N. Evaluation of knowledge, practices, and possible barriers among healthcare providers regarding medical waste management in Dhaka, Bangladesh. Med Sci Monit. 2014;20:2590-7.

11. Kishore J, Agarwal R, Kohli C, Sharma PK, Kamat N, Tyagi S. Status of biomedical waste management in nursing homes of Delhi, India. J Clin Diagn Res. 2014;8(3):56-8.

12. Alijabre SH, Hoffmann F, Almorzog BS, Mikiling L, Alabdulatif M, Al-Quorain AA. Hospital generated waste: an assessment of the awareness of hospital staff. J Fam Community Med. 2002;9(1):47-50.

13. Yadavannavar M, Berad AS, Jagirdar P. Biomedical waste management: a study of knowledge, attitude, and practices in a tertiary health care institution in Bijapur. Indian J Community Med. 2010;35(1):1701 .

Cite this article as: Holla R, Darshan BB, Sorake N, Unnikrishnan B, Thapar R, Mithra P, Kumar N, Kulkarni $\mathrm{V}$, Kumar A. Knowledge and practices regarding biomedical waste management among healthcare professionals in tertiary care hospitals of Mangalore, India. Int J Community Med Public Health 2015;2:6569. 